\title{
CLARIFICATION OF MUNICIPAL SEWAGE WITH FERRIC CHLORIDE: THE NATURE OF COAGULANT SPECIES
}

\author{
A.G. El Samrani *(a) ${ }^{(\text {B.S. Lartiges }}{ }^{(\mathrm{a})}$, E. Montargès-Pelletier *, \\ V. Kazpard*, O. Barrès * and J. Ghanbaja \\ *Laboratoire Environnement et Minéralurgie (LEM-ENSG) Pôle de l'Eau \\ 15, Avenue du Charmois -BP 40 - 54501 Vandœuvre Cedex, FRANCE
}

¥ Service Commun de Microscopie Electronique à Transmission. Faculté des Sciences.

Université Henri Poincaré. BP 239. 54500 Vandœuvre Cedex, FRANCE.

(a) To whom correspondence should be addressed

E-mail: bruno.lartiges@get.omp.eu 


\begin{abstract}
The nature of coagulant species formed in the system ferric chloride/municipal sewage was explored with Transmission Electron Microscopy coupled with Energy Dispersive X-ray Spectroscopy (TEM-EDS) and Fe K-edge X-ray Absorption spectroscopy. Jar-test data combined with chemical analysis of supernatant (dissolved organic carbon, iron, and phosphorus) and Fourier-Transform-Infrared spectroscopy (FTIR) of freeze-dried sediment, provided a detailed description of sewage clarification. The results showed that the nature of coagulant species evolves with Fe concentration. Up to the optimum turbidity removal, mainly iron dimers linked with one phosphate anion are detected. At higher dosages, polymers of hydrolyzed $\mathrm{Fe}$ appear even though $\mathrm{PO}_{4}$ still participates in the formation of coagulant species. TEM observation of freeze-dried sediments corroborates such an evolution of Fe speciation. EDS analyses reveal that minute amounts of sulfur, silicon, aluminum, and calcium, are associated with the coagulant species. Even though the coagulant species change with Fe concentration, the destabilization mechanism, inferred from electrophoretic mobility of aggregates and the evolution of floc size under cyclic changes of stirring conditions, could be identified to a charge neutralization of sewage colloids in the whole range of coagulant concentration.
\end{abstract}

\title{
KEYWORDS
}

Coagulant species, Coagulation, Ferric Chloride, Hydrolysis, Phosphate, Sewage treatment 


\section{INTRODUCTION}

When added to water, aluminum and iron salts dissociate and react to yield hydrolysis products. As first evidenced by Mattson in 1928, these hydrolysis products form the coagulant species that remove turbidity and color during water treatment [1]. Recent ${ }^{27} \mathrm{Al}$ Nuclear Magnetic Resonance (NMR), Fe K-edge Extended X-ray absorption fine structure spectroscopy (EXAFS), and Small Angle X-ray Scattering (SAXS) investigations, have partly unravelled the complex aqueous chemistry of aluminum-based and iron-based coagulants [2], [3], [4], [5]. Thus, in the presence of chloride or nitrate ions, addition of sodium hydroxide to an aluminum solution produces monomers, dimers, dissolved polynuclear species such as $\mathrm{Al}_{13}$ polycations, and inorganic metal aggregates that correspond to clusters of $\mathrm{Al}_{13}$ units [2],

[3]. Trimeric and tetrameric species of hydrolyzed aluminum are also likely to be present in the speciation scheme according to the parallel hydrolytic behavior of aluminum and gallium [6]. Likewise, the hydrolysis of $\mathrm{FeCl}_{3}$ solutions proceeds with monomers, dimers, double corner trimers, and polycations that consist in the arrangement of $24 \mathrm{Fe}$ atoms in a $\beta$-FeOOH local structure [5]. Further neutralization of the Fe solution induces the association of $\mathrm{Fe}_{24}$ polycations within fractal clusters [7].

However, the hydrolysis products formed upon base-neutralization of lab-prepared Al or Fe solutions may be significantly different from the coagulant species that promote colloid aggregation during water treatment. Indeed, simple inorganic anions present in natural waters such as $\mathrm{PO}_{4}$ or $\mathrm{SO}_{4}$, are known to alter the pathway of $\mathrm{Al} / \mathrm{Fe}$ hydrolysis [8], [9], [10]. For instance, an excess of sulfate ions in solution prevents the formation of $\mathrm{Al}_{13}$ polycations [10], whereas a sufficient amount of phosphate ions limits the hydrolysis of $\mathrm{Fe}^{3+}$ cations to the edge-sharing iron dimer stage [9], [11]. Preformed coagulant species may also be strongly modified during their attachment to the colloidal particles to be removed. In presence of silica nanospheres, $\mathrm{Al}_{13}$ polycations have been shown to depolymerize upon contact with the silica surface to yield tetrahedrally coordinated aluminosilicate sites [12]. Depolymerization of $\mathrm{Al}_{13}$ into monomers has also been observed when small organic ligands such as lactate, oxalate, or salicylate are present in solution [13], [14].

Until now, only a few studies have been devoted to the identification of true coagulant species formed during the treatment of natural waters. Thus, a combined ${ }^{27} \mathrm{Al}$ NMR and 
SAXS investigation of a lake water coagulated with pre-hydrolyzed aluminum, revealed that the natural organic matter had depolymerized most polynuclear Al species into uncondensed Al monomers [15]. Similarly, the Fe species found in flocs from two surface waters treated with ferric chloride, were reported to be poorly polymerized, Fe K-edge EXAFS indicating a predominance of single-corner-sharing trimers [16]. Unlike river or lake waters, municipal sewage provides a system with abundant organic matter and complexing anions that should extend the concentration range in which hydrolyzing coagulant species interact with the raw water content. In this work, we investigate the nature of coagulant species formed during the clarification of municipal sewage with a commercial ferric chloride. Sewage coagulation is assessed by jar-test, whereas the removal of dissolved organic matter and inorganic species is determined using carbon analysis and ICP-MS, respectively. Freeze-dried coagulated sediments are also examined by FTIR. The speciation of Fe within the aggregates is examined with Fe K-edge EXAFS and Transmission Electron Microscopy coupled with Energy Dispersive X-ray Spectrometry. The electrophoretic mobility of aggregates and the evolution of floc size under cycled-shear conditions, are also measured to provide some insight into the coagulation mechanism of municipal sewage with ferric chloride.

\section{EXPERIMENTAL SECTION}

\section{Sample collection}

Municipal sewage was taken from the inlet of Maxéville wastewater treatment plant (France). This plant deals with sewage from Nancy Urban Community and has a capacity of 300000 population equivalent. Grab samples were collected in 2 L polyethylene containers, and were used for experiments within 3 hours of sampling. A rough determination of Total Suspended Solid (TSS) content was obtained by drying duplicates of well-mixed $10 \mathrm{~mL}$ sewage samples at $105^{\circ} \mathrm{C}$ for at least 1 hour. Volatile Solid (VS) content was assessed by further heating the same samples at $550{ }^{\circ} \mathrm{C}$ for 3 hours. During the period of the study, TSS and VS averaged $750 \pm 32 \mathrm{mg} / \mathrm{L}$ and $450 \pm 27 \mathrm{mg} / \mathrm{L}$, respectively. The $\mathrm{pH}$ of municipal sewage was about $7.8 \pm 0.2$.

\section{Coagulation procedure}


A commercial ferric chloride coagulant, CLARFER (Elf-Atochem, France), was used as a coagulating agent. It is an unhydrolyzed iron salt solution, $38 \%$ wt in $\mathrm{FeCl}_{3}$ with a density of 1.4. Coagulation tests were conducted in 1L baffled reactors of known power dissipation characteristics [12]. The stirring rate was fixed at $100 \mathrm{rpm}$ which corresponds to a mean velocity gradient $\mathrm{G}=135 \mathrm{~s}^{-1}$. The coagulant was added under agitation as pure solution using a micro-pipette (Eppendorf), and mixing was continued for 20 minutes. Coagulated suspensions were then allowed to settle in graduated Imhoff cones for 30 minutes.

\section{Supernatant characterization}

After the designated settling period, $50 \mathrm{~mL}$ of supernatant were withdrawn with a syringe from about $25 \mathrm{~mm}$ below the free surface. Residual turbidity (Ratio XR Turbidimeter Hach Chemical Comp.) and pH (Meter Lab PHM 210 Tacussel) were measured, while the remaining supernatant was filtered with $0.2 \mu \mathrm{m}$ pore size cellulose acetate filters (MachereyNagel) for ICP-MS analysis (Jobin-Yvon 70 type B model) of dissolved Fe and P concentrations. Dissolved Organic Carbon (DOC) was also assessed with a Dorhmann 190 analyzer.

The Electrophoretic Mobility of unsettled colloids was determined with a Zetaphoremeter III (Sephy, France) equipped with a CCD camera. The top $400 \mathrm{~mL}$ of supernatant were first collected by siphoning and centrifuged at $2880 \mathrm{~g}$ for 5 minutes (Eppendorf Centrifuge 5804). The centrifugate was then re-suspended in 50mL of supernatant before being pumped to the measurement cell.

\section{Sediment characterization}

Following volume measurement, the sediments were collected and freeze-dried (Benchtop 3.3 EL105 Sentry). For infrared analysis, 1mg of freeze dried sediment was mixed with $250 \mathrm{mg} \mathrm{KBr}$ (FTIR grade, Merck), and a pellet was prepared using a press connected to a vacuum pump. Transmission Fourier-Transform InfraRed (FTIR) spectroscopy was conducted with a Bruker IFS 55 spectrophotometer. The spectra were recorded in the 4000$400 \mathrm{~cm}^{-1}$ range with 200 scans collected at $2 \mathrm{~cm}^{-1}$ resolution. 
Elemental microanalyses of freeze-dried coagulated sewage were carried out with a Philips CM20 Transmission Electron Microscope equipped with an Energy Dispersive X-ray Spectrometer (EDAX). A sample of freeze-dried sediment was first re-suspended in ethanol under ultrasonication, and a drop of suspension was then evaporated on a carbon-coated copper grid. For each coagulant concentration, about 50 TEM-EDS spectra were recorded with a $70 \mathrm{~nm}$ probe size at different locations within the organic matrix of aggregates. $\mathrm{K}_{\alpha} \mathrm{X}$ ray emission lines of $\mathrm{Na}, \mathrm{Al}, \mathrm{Si}, \mathrm{Mg}, \mathrm{Ca}, \mathrm{S}, \mathrm{P}, \mathrm{Cl}$ and $\mathrm{Fe}$ were integrated and quantified after a $30 \mathrm{~s}$ counting time. In order to improve the accuracy of Fe/P molar ratio determinations, EDS calibration standards were prepared from freeze-dried precipitates obtained by hydrolyzing ferric chloride in the presence of various amounts of $\mathrm{Na}_{2} \mathrm{HPO}_{4}, 2 \mathrm{H}_{2} \mathrm{O}$ (Labosi).

Fe K-edge EXAFS measurements were carried out at LURE (Orsay, France) on the D44 station of the DCI storage ring (1.85 GeV and $300 \mathrm{~mA})$. Freeze-dried sediment was studied as solid pellets mixed with cellulose. X-ray absorption spectra were recorded at room temperature in the transmission mode around the Fe K edge $(7133 \mathrm{eV})$ from 7000 to $8100 \mathrm{eV}$ with $2 \mathrm{eV}$ steps and $2 \mathrm{~s}$ collecting time. EXAFS data reduction was carried out according to standard procedures [17] with software written by Michalowicz [18]. A Kaiser window (3.5$14.7 \AA^{-1}$ ) was used for deriving Fourier transforms from EXAFS spectra. The Radial Functions (RDF) thus obtained are not corrected for phase shifts, which leads to peaks shifted down by about $0.3 \AA$ compared with crystallographic distances. For modeling experimental spectra, theoretical phase shifts and amplitude backscattering functions were determined from $\gamma$-FeOOH. The structural and chemical parameters $\mathrm{Rj}$ (distances from the central atom), $\mathrm{Nj}$ (number of atoms), and nature of atomic neighbors in the jth shell around Fe, were determined by least-squares fitting of partial EXAFS spectra. The uncertainties on $\mathrm{R}$ and $\mathrm{N}$ are $0.06 \AA$ and $10 \%$, respectively.

\section{Aggregate size measurements}

The dynamics of aggregation was investigated by following the floc size distribution under various conditions of agitation. Floc size distributions were measured on-line in the range 1.2-600 $\mu \mathrm{m}$ with a Malvern MasterSizer (Malvern Instruments) based on Fraunhoffer diffraction. To avoid multiple scattering in the measurement cell, the sewage colloids were first diluted with the supernatant of centrifuged sewage (7120g for 35 min-Beckman-L8-55M Ultracentrifuge) to yield a suspended solid concentration of $150 \mathrm{mg} / \mathrm{L}$. This suspension was 
agitated in the baffled reactor, passed through the analyzer beam with a peristaltic pump located downstream the measurement cell, and then recycled to the reactor. Previous investigations have revealed that shearing in the transport tubing alters the size distribution of flocs in the reactor [19]. However, the same studies also showed that the relative variations in floc size measured with the particle sizer remain correlated with the changes in agitation conditions within the reactor [19]. As a consequence, on-line floc size measurements are appropriate to follow the evolution of floc size as a function of time and agitation conditions. A pumping flow rate of $55 \mathrm{~mL} / \mathrm{min}$, and a transport tubing (Masterflex) of $4.6 \mathrm{~mm}$ in internal diameter and $16 \mathrm{~cm}$ in length were selected for the experiments. Size measurements were averaged over $1 \mathrm{~s}$ and taken every $2 \mathrm{~s}$. The results obtained are volume based and they are represented as particle volume versus sphere diameter of equivalent volume.

\section{RESULTS AND DISCUSSION}

\section{Sewage clarification}

Figure 1 shows typical results obtained during jar test studies of Nancy municipal sewage. As illustrated in figure 1a, destabilization occurs from low coagulant dosages since residual turbidity decreases continuously to reach an almost constant value over the range 7.7 $10^{-4}-1.810^{-3} \mathrm{M}$. The ferric chloride concentration of $7.710^{-4} \mathrm{M}$ can then be set as the optimum coagulant concentration (OCC). Above $2.210^{-3} \mathrm{M}$, further coagulant addition induces the restabilization of the suspension: the residual turbidity increases strongly and exceeds the value measured for untreated settled sewage. The inverse pattern is observed for sediment volume: it builds up rapidly at low coagulant dosages, then more slowly above the occ, and finally diminishes gradually as the suspension is restabilized. $\mathrm{pH}$ measurements reveal three domains . For concentrations $\leq 4.510^{-4} \mathrm{M}$, the $\mathrm{pH}$ decreases linearly from 7.9 to 7 , for $4.510^{-4} \leq[\mathrm{Fe}] \leq 1.710^{-3} \mathrm{M}$, the $\mathrm{pH}$ decreases with a lesser slope down to a $\mathrm{pH}$ value of 5.5; it then exhibits a drop from $\mathrm{pH} 5$ to $\mathrm{pH} 3$ around the restabilization concentration (fig. 1b). On the other hand, residual $\mathrm{Fe}$ is negligible with values close to the detection limit in the destabilization domain, whereas it increases rapidly above a $2.210^{-3} \mathrm{M}$ coagulant concentration (fig. 1b).

Such results are in agreement with the coagulation behavior classically described with metal hydrolyzing coagulants [20]. Indeed, for aluminum or iron salts, efficient particle 
destabilization occurs when hydrolysis products acting as coagulant species can be formed. In our case, the initial $\mathrm{pH}$ of the suspension $(7.8 \pm 0.2)$ and the high iron concentration of the commercial coagulant, facilitate hydrolysis upon ferric chloride addition to municipal sewage. Capture of $\mathrm{OH}^{-}$ions during hydrolysis lowers the $\mathrm{pH}$ and enables the formation of iron polymeric species that promote turbidity removal [21]. As coagulant dosage increases, the buffer capacity of the solution is eventually exceeded. The $\mathrm{pH}$ then drops drastically provoking the formation of less or non-hydrolyzed metal ions much less effective for aggregation and hence, the restabilization of the suspension. Interestingly, the $\mathrm{pH}$ of optimum coagulation is about 6.5 , which falls in the $5-7 \mathrm{pH}$ range of adequate turbidity removal usually reported for iron(III)-based coagulants [16], [22], [23].
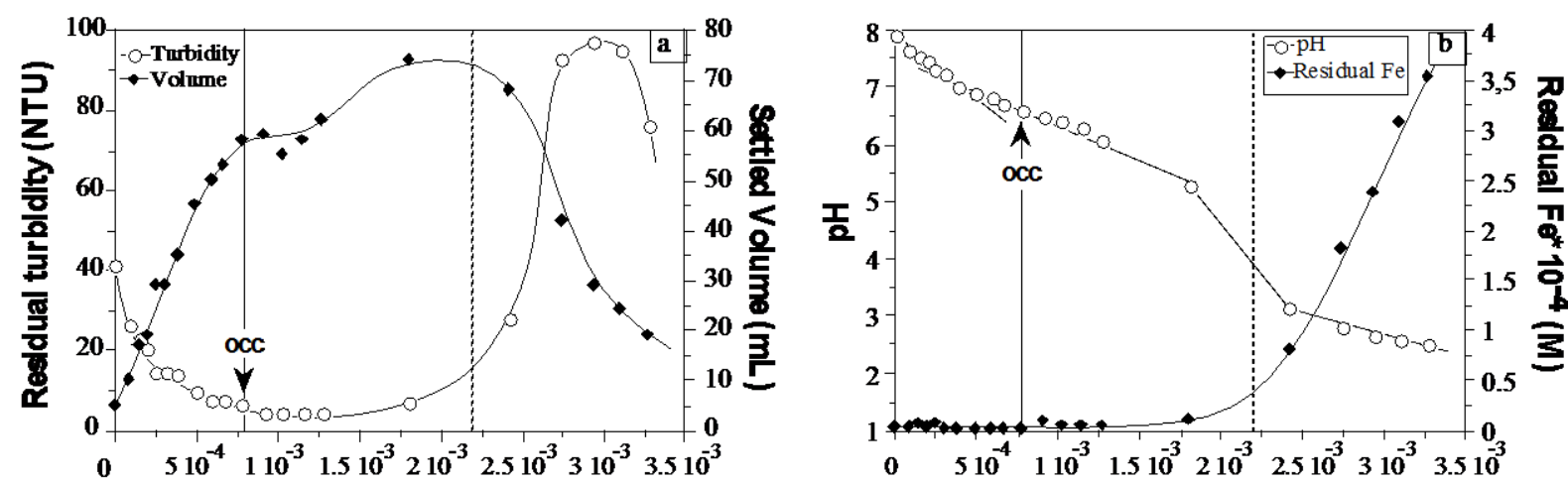

Ferric Chloride (M)

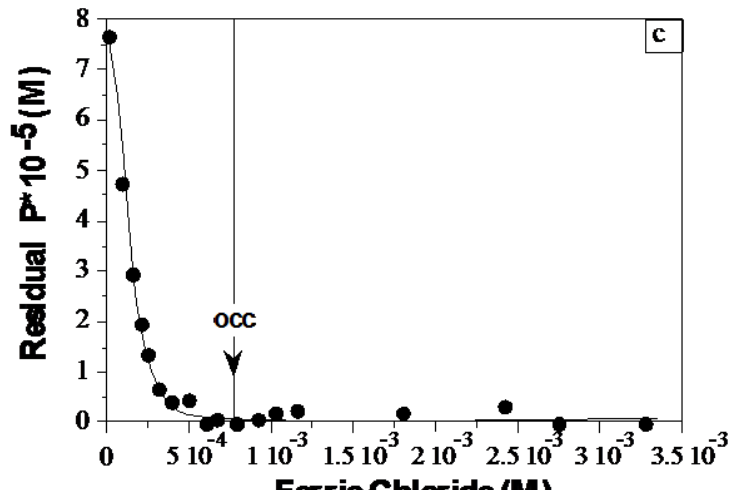

Ferric Chloride (M)

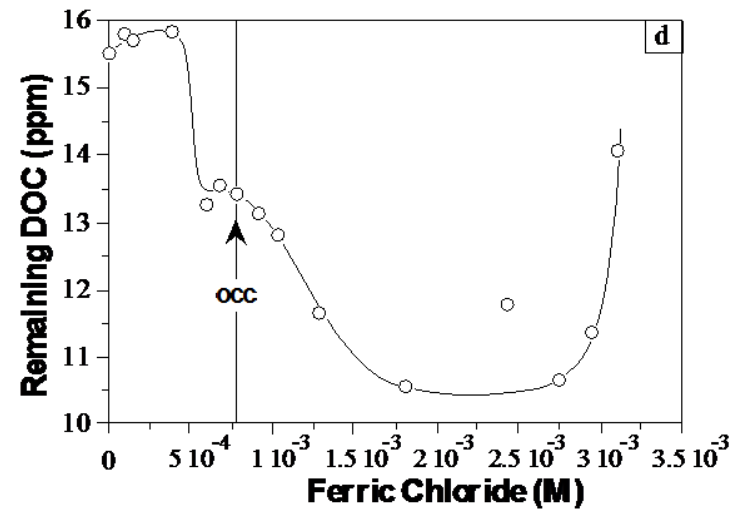

Figure 1. Evolution as a function of ferric chloride concentration of (a) Residual turbidity and settled volume, (b) $\mathrm{pH}$ and residual iron, (c) residual phosphorus, and (d) residual dissolved organic matter.

Figure 1c shows the evolution of residual $\mathrm{P}$ as a function of ferric chloride concentration. The sharp decrease in phosphorus concentration observed at low coagulant dosages is expected as iron salts are known to interact strongly with phosphate compounds [9]. The removal of dissolved $\mathrm{P}$ is completely achieved at about neutral $\mathrm{pH}$ for $[\mathrm{Fe}]=610^{-4}$ 
$\mathrm{M}$, which can be related to the linear decrease in $\mathrm{pH}$ with coagulant concentration in the [0-6 $10^{-4} \mathrm{M}$ ] range (fig. $\left.1 \mathrm{~b}\right)$. Given the $\mathrm{pKa}$ values of the phosphate anions $\left(\mathrm{pKa}\left(\mathrm{H}_{2} \mathrm{PO}_{4}^{-}\right)=2.2\right.$; $\left.\mathrm{pKa}\left(\mathrm{HPO}_{4}^{2-}\right)=7.2\right)$, the predominant species above $\mathrm{pH} 7.2$ is $\mathrm{HPO}_{4}{ }^{2-}$. Although the exact mechanism of phosphate removal with hydrolyzed Fe is not known, it is possible that the binding of $\mathrm{HPO}_{4}{ }^{2-}$ to $\mathrm{Fe}$ oligomeric species implies the release of a proton, thus reinforcing the decrease in $\mathrm{pH}$ due to ferric chloride hydrolysis.

DOC removal occurs in three main stages (fig. 1d). At low coagulant concentrations, DOC increases slightly until $[\mathrm{Fe}]=3.810^{-4} \mathrm{M}$. In that same range, residual turbidity was noted to decrease strongly. It can then be inferred that organic particulates are more effectively removed than dissolved organic matter in municipal sewage, which agrees with similar results established with natural organic matter (NOM) from various surface waters [24], [25], [26], [16]. Increasing the coagulant dosage induces the destabilization of DOC: a reduction of about $20 \%$ of initial DOC is first achieved just before the OCC; then, DOC diminishes again gradually at higher ferric chloride concentrations to reach $40 \%$ removal at $[\mathrm{Fe}]=210^{-3} \mathrm{M}$. This latter decrease in DOC yields settleable aggregates which accounts for the supplementary increase in settled volume beyond the OCC (fig. 1a). Finally, DOC is again released in the clarified water at a coagulant dosage slightly higher than the restabilization concentration determined from the evolution of turbidity removal.

It should first be noted that DOC removal starts occurring once almost all phosphorus is eliminated from the solution by Fe hydrolysis products, which agrees with the numerous examples of competitive interaction between phosphate compounds and natural organic matter for metal oxides reported in the literature [27], [28], [29], [30]. In particular, the presence in solution of phosphate species is known to substantially inhibit NOM adsorption on iron oxyhydroxides especially above $\mathrm{pH} 7$ [31].

Therefore, it is likely that, at low coagulant concentrations and basic $\mathrm{pH}$, phosphorus uptake by Fe polymeric species significantly hinders the removal of dissolved organic matter. On the other hand, the two steps of DOM elimination could be explained by the presence of two kinds of organic matter. Indeed, NOM is known to be a very complex mixture of organic components the relative amounts of which can influence destabilization performance. For instance, the hydrophobic fraction is more easily destabilized than hydrophilic compounds [24], [26], polyhydroxyaromatics are more amenable to removal by ferric chloride than polysaccharides [16], and high content of carboxylic functional groups within organic molecules requires a higher coagulant demand [23], [22], [32]. 
The FTIR spectra of freeze-dried sediments provide further evidence for a sequential elimination of dissolved organic matter. All peaks observed and the corresponding assignments are listed in Table 1.

Table 1. Transmission Fourier -Transformed Infrared bands of freeze-dried sediments of treated sewage water with ferric chloride. Assignments band as they given in literature.

\begin{tabular}{|c|c|c|}
\hline Band $\left(\mathrm{cm}^{-1}\right)$ & Assignment proposed & Reference \\
\hline 3400 & $\begin{array}{l}\text { Water } \mathrm{OH} \text {, Phenolic, aliphatic and with a partial } \\
\text { contribution of N-H }\end{array}$ & $\begin{array}{l}\text { Niemeyer et al., } 1992 \\
\text { [33] }\end{array}$ \\
\hline $\begin{array}{l}2920 \\
2955 \\
2850\end{array}$ & $\begin{array}{l}\text { C-H asymmetric stretching in } \mathrm{CH}_{2} \\
\text { C-H asymmetric stretching in } \mathrm{CH}_{3} \\
\text { C-H symmetric stretching in } \mathrm{CH}_{2}\end{array}$ & $\begin{array}{l}\text { Gu et al., } 1994[30] \\
\text { Dignac et al., } 2000[34]\end{array}$ \\
\hline $\begin{array}{l}1725 \\
1650\end{array}$ & $\begin{array}{l}\mathrm{C}=\mathrm{O} \text { in } \mathrm{COOH} \text { groups } \\
\text { Strong asymmetrical stretch of } \mathrm{COOH} \text { and } \mathrm{C}=\mathrm{O} \\
\text { vibration in secondary amides }\end{array}$ & $\begin{array}{l}\text { Lobartini and Tan, } 1988 \\
{[35]}\end{array}$ \\
\hline 1544 & $\begin{array}{l}\text { Asymmetrical stretching of }-\mathrm{C}=\mathrm{O} \text { in the } \\
\text { complexed carboxylate groups } \\
\text { Symmetrical stretching of }-\mathrm{C}=\mathrm{O} \text { in the } \\
\text { complexed carboxylate groups }\end{array}$ & $\begin{array}{l}\text { Ricca and Severini, } \\
1993 \text { [36] } \\
\text { Gu et al., } 1995 \text { [37] }\end{array}$ \\
\hline 1462 & $\mathrm{OH}$ deformation in phenolic groups & $\begin{array}{l}\text { Yost et al., } 1990[38] \\
\text { Gu et al., } 1995[37] \\
\text { Zhou et al., } 2000 \text { [39] }\end{array}$ \\
\hline 875 & $\mathrm{P}-\mathrm{OH}$ in $\mathrm{H}_{2} \mathrm{PO}_{4}^{-}$and $\mathrm{H}_{3} \mathrm{PO}_{4}$ & $\begin{array}{l}\text { Tjedor-Tjedor and } \\
\text { Anderson, } 1990[40]\end{array}$ \\
\hline $\begin{array}{l}475,615, \\
670\end{array}$ & $\alpha-\mathrm{FeOOH}$ (goethite) and $\beta-\mathrm{FeOOH}$ (akaganeite) & $\begin{array}{l}\text { Dousma and de Bruyn, } \\
1976 \text { [41] } \\
\text { Zhang et al., } 1993 \text { [42] }\end{array}$ \\
\hline
\end{tabular}

As shown in figure 2, the spectra exhibit similar features although the relative intensities of individual bands vary noticeably as a function of ferric chloride concentration. Thus, absorption at $2920 \mathrm{~cm}^{-1}$ and $2850 \mathrm{~cm}^{-1}$ (C-H asymmetric and symmetric stretching in $\mathrm{CH}_{2}$, respectively) decrease at low coagulant dosages, while the intensity of the peak at 2955 $\mathrm{cm}^{-1}$ (C-H asymmetric stretching in $\mathrm{CH}_{3}$ ) remains nearly constant. In other terms, the $\mathrm{CH}_{2} / \mathrm{CH}_{3}$ relative abundance within the coagulated sediment decreases as a function of ferric 
chloride concentration, indicating that molecules with long aliphatic chains are removed prior to organic structures presenting a higher branching level. This can be further illustrated by the evolution of peak intensity ratios $\mathrm{I}_{2920} / \mathrm{I}_{2955}$ and $\mathrm{I}_{2850} / \mathrm{I}_{2955}$ (fig. 3a). Both ratios exhibit similar trends and reach a stable value above $[\mathrm{Fe}]=1.210^{-3} \mathrm{M}$.

Absorbance peaks related to carboxylic functional groups also evolve distinctly with coagulant concentration: the band at $1725 \mathrm{~cm}^{-1}$ ( $\mathrm{C}=\mathrm{O}$ stretching vibration in $\mathrm{COOH}$ groups), initially present as a well defined shoulder, becomes gradually weaker around OCC, and is then replaced by a better resolved peak at high dosages. In parallel, the band at $1570 \mathrm{~cm}^{-1}$ (asymmetrical stretching of $\mathrm{C}=\mathrm{O}$ in $\mathrm{COOH}$ groups) disappears progressively with increasing ferric chloride concentration and is virtually absent beyond $[\mathrm{Fe}]=210^{-3} \mathrm{M}$. The peak at 1544 $\mathrm{cm}^{-1}$, assigned to asymmetrical stretching of $\mathrm{C}=\mathrm{O}$ in complexed carboxylate groups, remains well defined up to OCC, and then broadens and diminishes in intensity at higher coagulant concentration. Similarly, the peak at $1410 \mathrm{~cm}^{-1}$ (symmetrical stretching of $\mathrm{C}=\mathrm{O}$ in complexed carboxylate groups) increases sharply to reach a maximum at $[\mathrm{Fe}]=1.210^{-3} \mathrm{M}$, before decreasing at higher ferric chloride concentrations. Such modifications can be readily explained by the effect of $\mathrm{pH}$ on the binding capacity of carboxylic groups.

At the $\mathrm{pH}$ of untreated municipal sewage, carboxylic moieties are deprotonated and available for association with Fe hydrolysis products [43], [37]. As a result, absorbance bands assigned to complexed carboxylate groups become increasingly dominant with coagulant concentration. As iron hydrolysis takes place, the $\mathrm{pH}$ is lowered and $\mathrm{COO}^{-}$convert to $\mathrm{COOH}$ functional groups. Carboxyl groups are then less involved in complexation reactions with iron (III) hydrolyzed species, which leads to an enhanced absorption of $\mathrm{COOH}$ groups and weaker bands for complexed carboxylates. Such an evolution can also be visualized by plotting the ratios of peak heights of complexed carboxylates and carboxyl groups.

Thus, figure $3 \mathrm{~b}$ shows that $\mathrm{I}_{1410} / \mathrm{I}_{1725}$ and $\mathrm{I}_{1544} / \mathrm{I}_{1725}$ increase with coagulant dosage to a maximum around $\mathrm{OCC}$, and decrease upon further increase in Fe concentration. Finally, the minor peak at $1310 \mathrm{~cm}^{-1}$, previously assigned to asymmetric $\mathrm{COO}^{-}$stretch affected by $\mathrm{Ca}^{2+}$, $\mathrm{Mg}^{2+}$ cations [33], gradually disappears with ferric chloride concentration, suggesting that substitutions between $\mathrm{Fe}$ hydrolyzed products and bivalent cations complexed with carboxylic moieties, may also occur. 


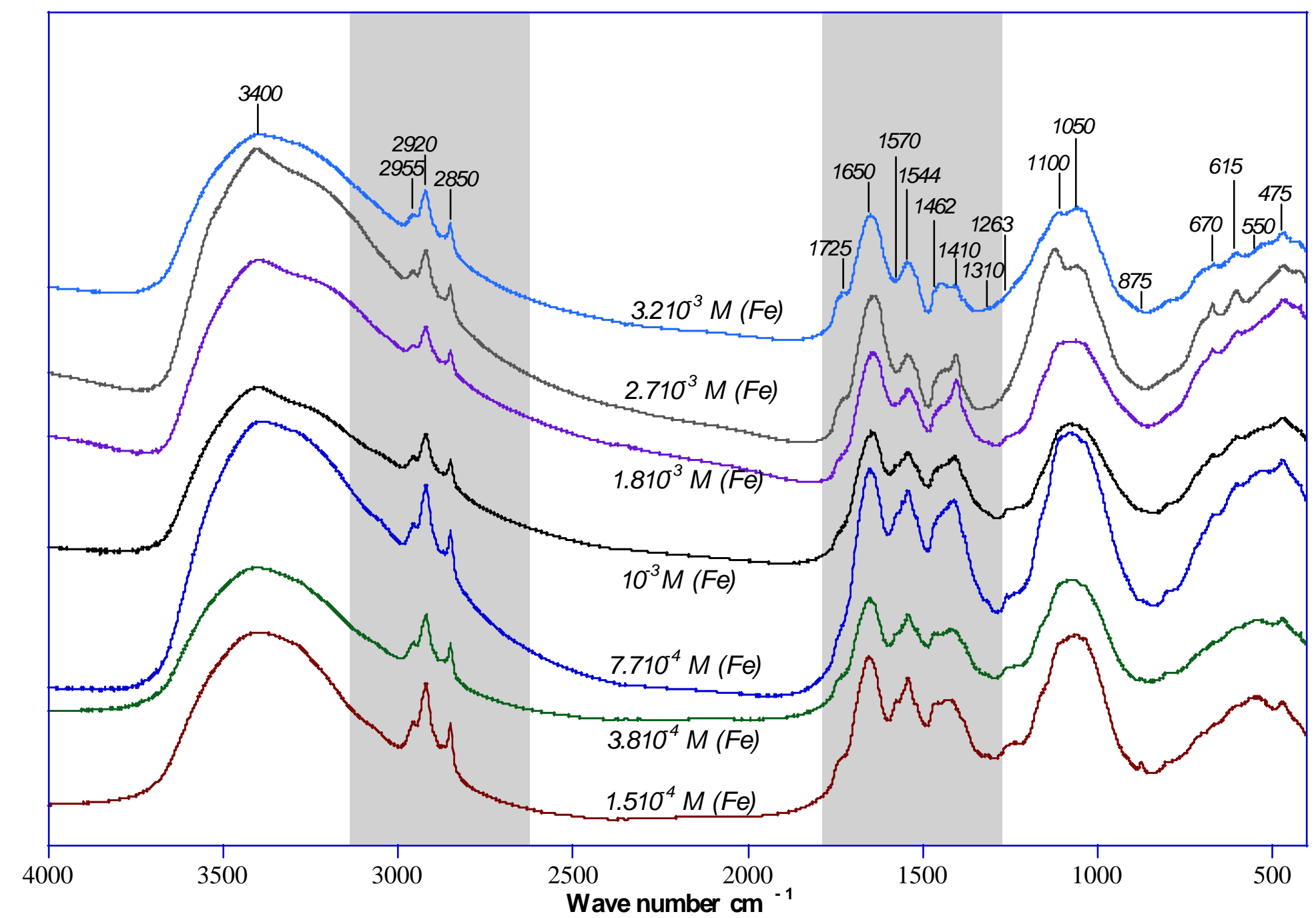

Figure 2. FTIR spectra of freeze dried sediments obtained with increased iron concentration. 

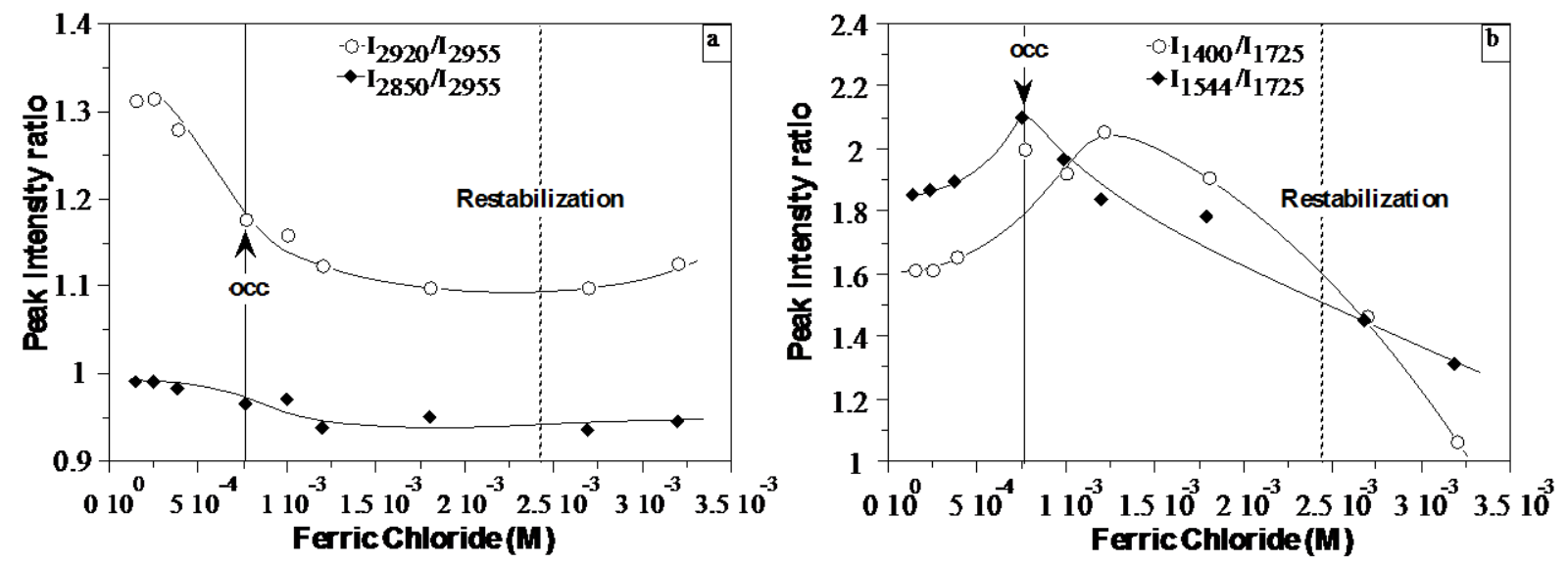

Figure 3. (a) Variation of peak intensity ratio for symmetric and asymmetric $\mathrm{CH}_{2}(2850$ and $2920 \mathrm{~cm}^{-1}$ ) and $\mathrm{CH}_{3}$ groups in the sediments as a function of ferric chloride. (b) Variation of peak intensity ratio of symmetric and asymmetric carboxylate $\left(1400\right.$ and $\left.1544 \mathrm{~cm}^{-1}\right)$ and $\mathrm{COOH}\left(1725 \mathrm{~cm}^{-1}\right)$ groups in the sediments as a function of ferric chloride.

\section{Identification of coagulant species}

Examination of infrared spectra also provides some information about the nature of coagulant species. Peaks at 475, 615, and $670 \mathrm{~cm}^{-1}$, which are more pronounced above OCC, can be compared with those reported for iron oxyhydroxides such as $\alpha-\mathrm{FeOOH}$ (goethite) and $\beta-\mathrm{FeOOH}$ (akaganeite) [41], [42]. Interestingly, EXAFS studies of ferric chloride hydrolysis have shown that the local structure of Fe-polymeric species resembles that of akaganeite and/or goethite [44], [45], [5]. On the other hand, the absorption band at $875 \mathrm{~cm}^{-1}$, tentatively assigned to $\mathrm{P}-\mathrm{OH}$ stretching vibrations [40], [46], can be distinguished in the $\mathrm{Fe}$ concentration range of phosphorus removal. Other contributions which would unambiguously identify phosphate species in the sediment, can not be isolated from the spectra, particularly within the broad bands of the $1000-1150 \mathrm{~cm}^{-1}$ region.

Further insight into the formation of coagulant species can be obtained from TEMEDS observation of freeze-dried sediments. In comparison with recent advanced protocols developed for studying aquatic colloidal material (e.g. [47]), freeze-drying is not the least pertubing preparatory technique for TEM examination of hydrated samples. Still, electron micrographs shown in figure 4 reveal obvious changes in the morphology of coagulated sewage as a function of ferric chloride concentration. At low coagulant dosages (fig. 4a), the sediment appears as an organic matrix with dispersed electron-dense granules of about $80 \mathrm{~nm}$ in diameter. In the $\left[310^{-4}-810^{-4} \mathrm{M}\right]$ concentration range, these colloids grow slightly in size 
and form aggregates of $140 \mathrm{~nm}$ subunits bridging organic particulates (fig. $4 \mathrm{~b}$ and $4 \mathrm{c}$ ). At still higher dosages, the organic material of coagulated sewage seems to be enveloped in a diffuse film of nanocolloids (5-10 nm) (fig. 4d).

EDS analyses indicate that these colloids contain essentially iron and phosphorus with lesser amounts of silicon, calcium, sulfur, and aluminum. Such morphology and composition of Fe-granules are in accordance with previous observations of hydrous iron oxides formed in aquatic environments [48], [49] and engineered systems [50]. Thus, in the concentration range of phosphorus removal, the iron-rich colloids resemble both in size and composition those found in lakes [49] and in biological sludge treated with iron salts [50], whereas overdosages in ferric chloride yield nanocolloids similar to that observed in freshly precipitated iron hydroxide gel [4], [50]. The relative proportions of $\mathrm{Si}, \mathrm{Al}, \mathrm{S}$, and $\mathrm{Ca}$ incorporated in iron-rich colloids were found to vary from analysis to analysis without showing any definite trend with coagulant dosage. In contrast, the distributions of EDS peak intensity ratios of iron and phosphorus are clearly related to the amount of ferric chloride applied as coagulant (figure 5). For coagulant concentrations lower than $210^{-4} \mathrm{M}$, the average $\mathrm{Fe} / \mathrm{P}$ molar ratio in Fe-colloids is about 1. Iron (III) salts have long been used as phosphate removing agents, and systematic studies of phosphate precipitation have shown that, in presence of excess $\mathrm{PO}_{4}$ ions and at moderate acidity, one mole of phosphate is removed per mole of iron (III) [8], [51]. Slightly higher Fe-concentrations, $310^{-4} \leq[\mathrm{Fe}] \leq 810^{-4} \mathrm{M}$, reveal monomodal distributions of Fe/P ratios comprised between 2 and 4.5, with the mode of the distribution unexpectedly shifting toward lower values of $\mathrm{Fe} / \mathrm{P}$ with coagulant dosage. In that concentration range, phosphate is almost completely eliminated from solution and $\mathrm{pH}$ is close to 6.5. The elemental compositions found for Fe-colloids can then be compared with various results from the literature. Indeed, effective phosphate precipitation is known to occur for a $\mathrm{Fe} / \mathrm{P}$ molar ratio equal to 2 in the 5-7 $\mathrm{pH}$ range [51]. Likewise, Lienemann et al. (1999) reported that $\mathrm{PO}_{4}$ ions are stoichiometrically incorporated into hydrous iron oxide colloids such that $\mathrm{P} / \mathrm{Fe}=0.48 \pm 0.11$ at the oxic-anoxic interface of an eutrophic lake [48]. Furthermore, Fe K-edge and $\mathrm{P} \mathrm{K}$-edge EXAFS spectroscopy revealed that $\mathrm{PO}_{4}$ ions hinder the hydrolysis of $\mathrm{Fe}(\mathrm{III})$ at the edge-sharing iron dimer stage [9], [11]. The same studies suggested that the basic unit of the precipitate formed during hydrolysis of $\mathrm{Fe}$ (III) in presence of phosphate, corresponds to one $\mathrm{PO}_{4}$ tetrahedron bridging two Fe-dimers. Such observation is consistent with our Fe/P molar ratios close to 4 determined from EDS analyses. 

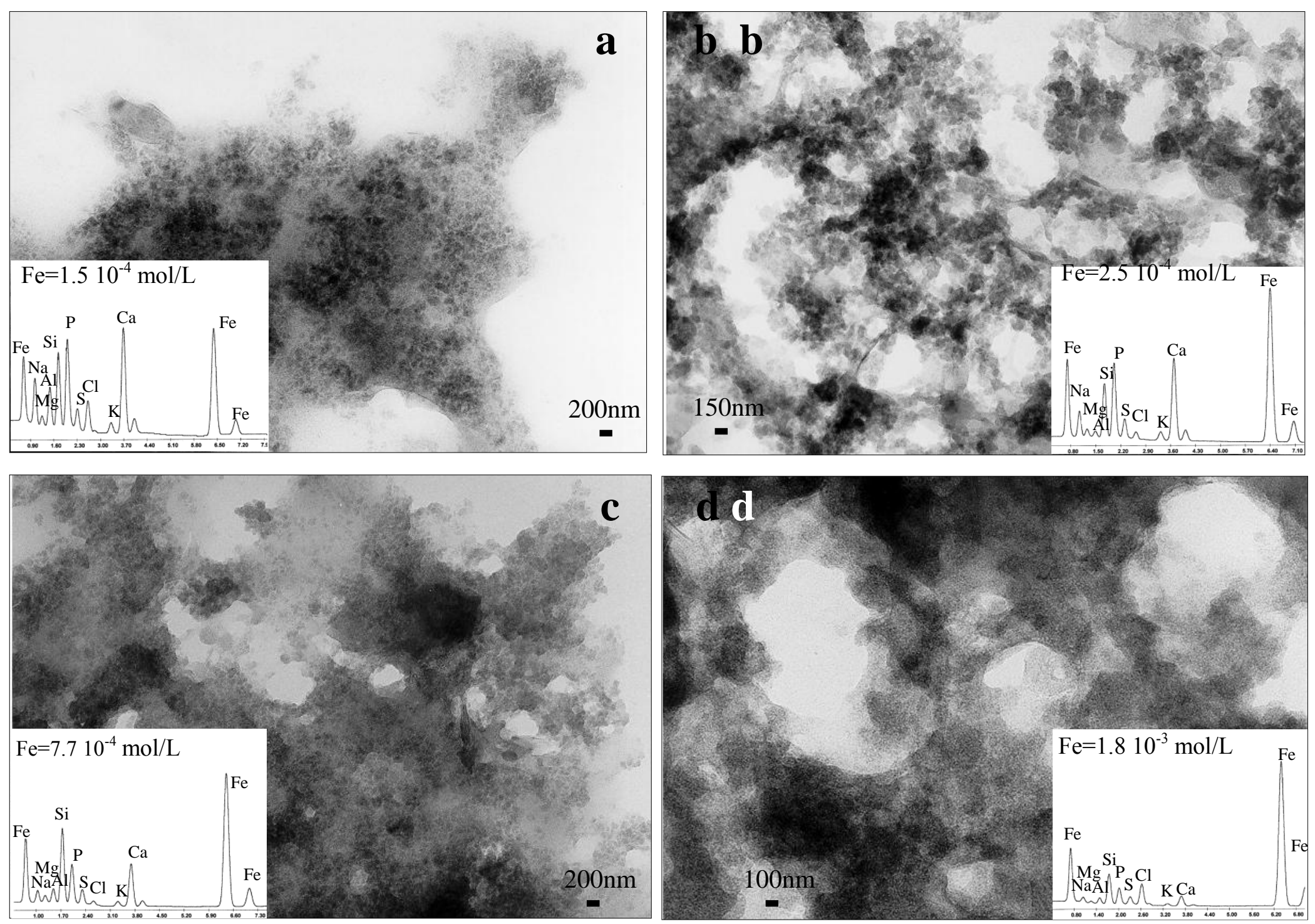

Figure 4. Electron micrographs and corresponding EDS spectra of aggregates obtained at various ferric chloride concentrations. 


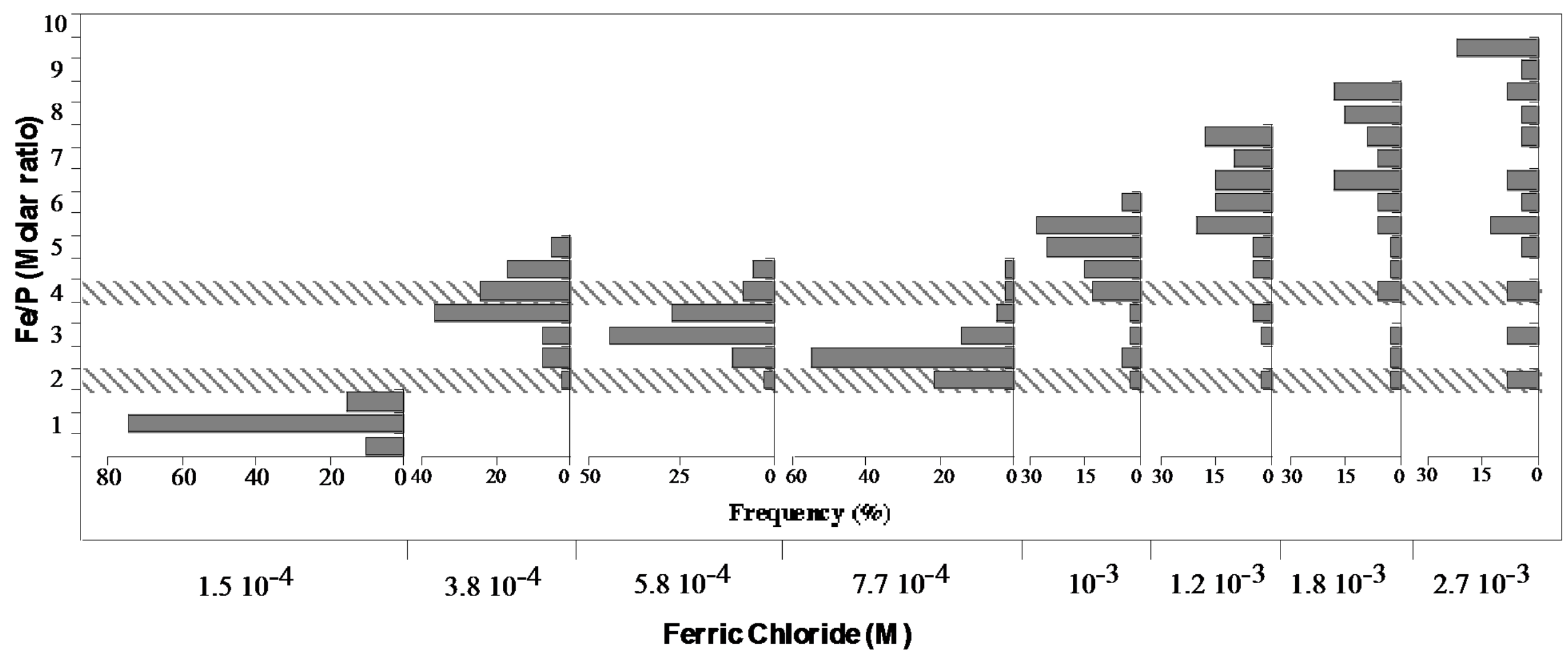

Figure 5. Frequency distributions of EDS peak intensity ratios of Fe/P determined inside aggregates obtained at various ferric chloride concentration. 
More recently, a stopped-flow investigation of the kinetics of iron(III)-phosphate reaction evidenced the existence of the tetranuclear complex $\mathrm{Fe}_{4}\left(\mathrm{PO}_{4}\right)(\mathrm{OH})_{2}\left(\mathrm{H}_{2} \mathrm{O}\right)_{16}{ }^{7+}$ in aqueous solution [52]. The formation of such a species is $\mathrm{pH}$ dependent and is favored at neutral $\mathrm{pH}$. This may then account for the decrease in average $\mathrm{Fe} / \mathrm{P}$ molar ratio in the $\left[310^{-4}\right.$ $810^{-4} \mathrm{M}$ ] concentration range as hydrolysis of added coagulant lowers the $\mathrm{pH}$. Above OCC, the peak intensity ratios become more uniformly spread out from $\mathrm{Fe} / \mathrm{P}=2$ to a $\mathrm{Fe} / \mathrm{P}$ maximum value which is roughly proportional to coagulant dosage. In addition, the average Fe/P molar ratio resumes its increase with ferric chloride concentration. A smoother distribution of EDS peak intensity ratios may originate in part from the formation of much smaller Fe-colloids in comparison with the EDS probe size. Actually, at overdosages, the formation of coagulant species should be essentially controlled by iron hydrolysis, complexing ions such as $\mathrm{PO}_{4}$ being simply trapped within Fe-polymeric chains.

EXAFS data at Fe K-edge provide complementary information about the status of iron at the local scale within coagulant species. The EXAFS spectra obtained from samples of sewage coagulated at underdosage $\left([\mathrm{Fe}]=2.510^{-4} \mathrm{~mol} / \mathrm{l}\right), \mathrm{OCC}$, and overdosage $([\mathrm{Fe}]=1.8$ $\left.10^{-3} \mathrm{~mol} / \mathrm{l}\right)$, are shown in figure $6 \mathrm{a}$.

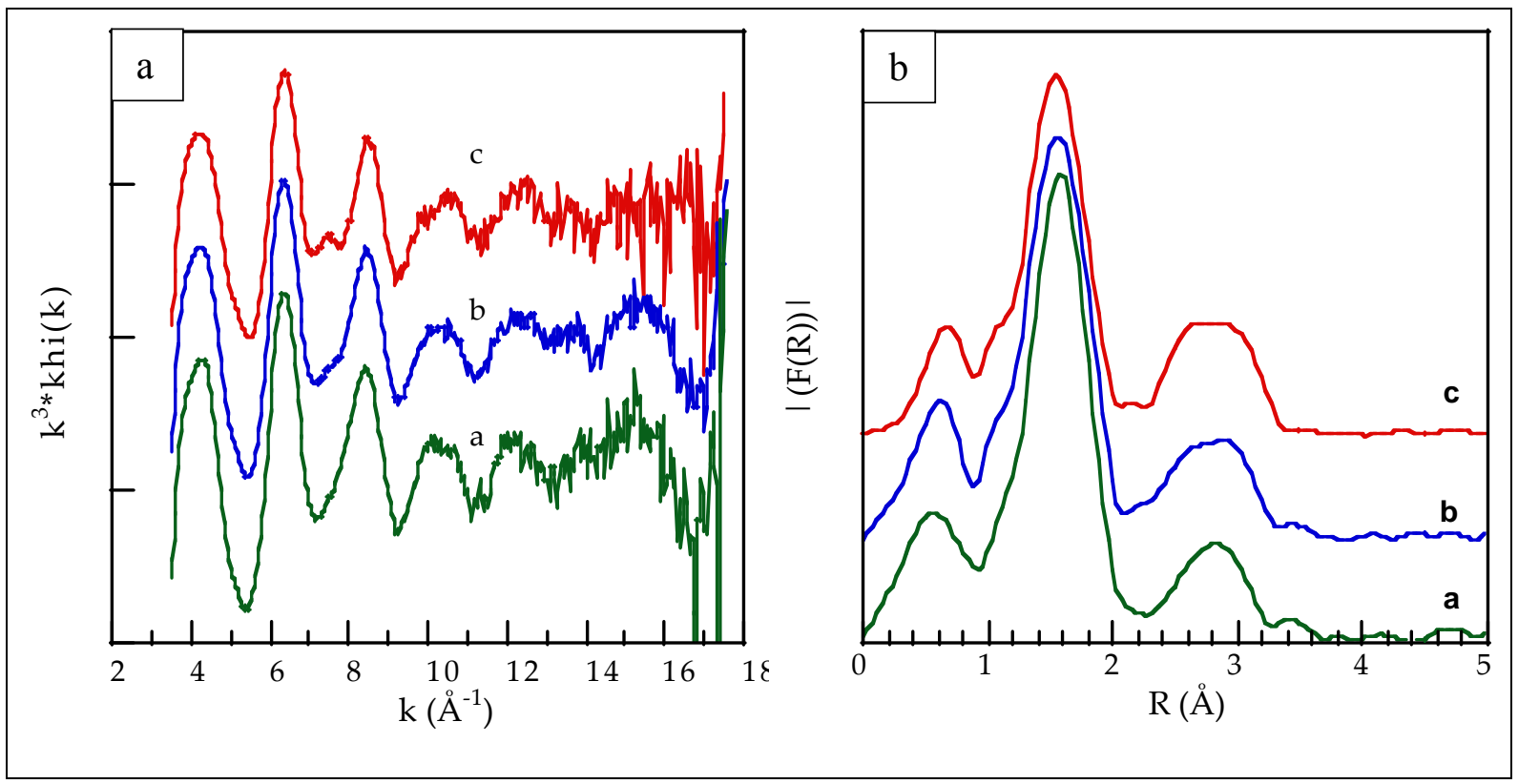

Figure 6. (a) EXAFS spectra of freeze dried sediments : a- underdosage $\left(2.510^{-4} \mathrm{M}\right)$, b- OCC $\left(7.710^{-4} \mathrm{M}\right)$, c- overdosage $\left(1.810^{-3} \mathrm{M}\right)$ and $(\mathrm{b})$ corresponding radial distribution functions. 
A slight modification of the EXAFS curves can be observed around $\mathrm{k}=7.4 \AA^{-1}$, a new resonance appearing in this range at high coagulant concentration. The corresponding radial distribution functions (RDF) exhibit two main peaks (fig. 6b): the first peak centered at $1.5 \AA$ (uncorrected from phase shift) corresponds to the first coordination shell of Fe atoms, i.e. 6 oxygen neighbors, and changes very little with Fe concentration. The second peak, which extends from 2.2 to $3.7 \AA$, corresponds to second coordination bondings with single- and double sharing of one hydroxyl group. Our analysis was focused on this second peak as it can reveal the nature, number, and distance of second neighbors of iron.

Figure 7a-c show the experimental and calculated curves for the second coordination shell of iron. The general shape of the three sine waves appears nearly constant as in this distance range, the oscillations mainly result from the presence of iron atoms whose backscattering amplitude is much higher than that of the other atoms supposed to be present, such as $\mathrm{C}$ and $\mathrm{P}$.

However, at low coagulant dosage, the fit of the second coordination shell implies that iron coagulant species are mainly dimers with edge-sharing and corner-sharing bondings at 3.08 and $3.60 \AA$, respectively. There was no evidence of trimeric units, characterized by the presence of a double corner-sharing distance at 3.45-3.5 $\AA$ [44]. Furthermore, a Fe-P contribution at $3.29 \AA$ could be evidenced $\left(\mathrm{N}_{\mathrm{Fe}-\mathrm{P}} \sim 0.7\right)$. Therefore, for this sample, the addition of ferric chloride to sewage could have induced the formation of iron dimers linked with one $\mathrm{PO}_{4}{ }^{3-}$ tetrahedron with monodentate or bidentate structure. At OCC, EXAFS analysis revealed an increase in the number of Fe-Fe pairs at $3.1 \AA$ such that $\mathrm{N} \sim 1.9$. Moreover, the fit was improved by using $\mathrm{P}$ and $\mathrm{C}$ as backscatterers in the second coordination sphere, suggesting that Fe-O-C and Fe-O-P bonds are also present in coagulant species.

Such Fe-C and Fe-P contributions can be related to the decrease of DOC and complete removal of phosphorus at OCC, and are consistent with TEM-EDS results. At $[\mathrm{Fe}]=1.810^{-3}$ mol/l, a new Fe-Fe contribution at $3.42 \AA$ appears that corresponds to trimeric units with double corner sharing. The presence of such a contribution indicates that the degree of polymerization of iron is higher at this concentration in accordance with FTIR spectra. Indeed, the double corner sharing trimer is a known precursor of akaganeite that forms upon hydrolysis of iron chloride [4]. 


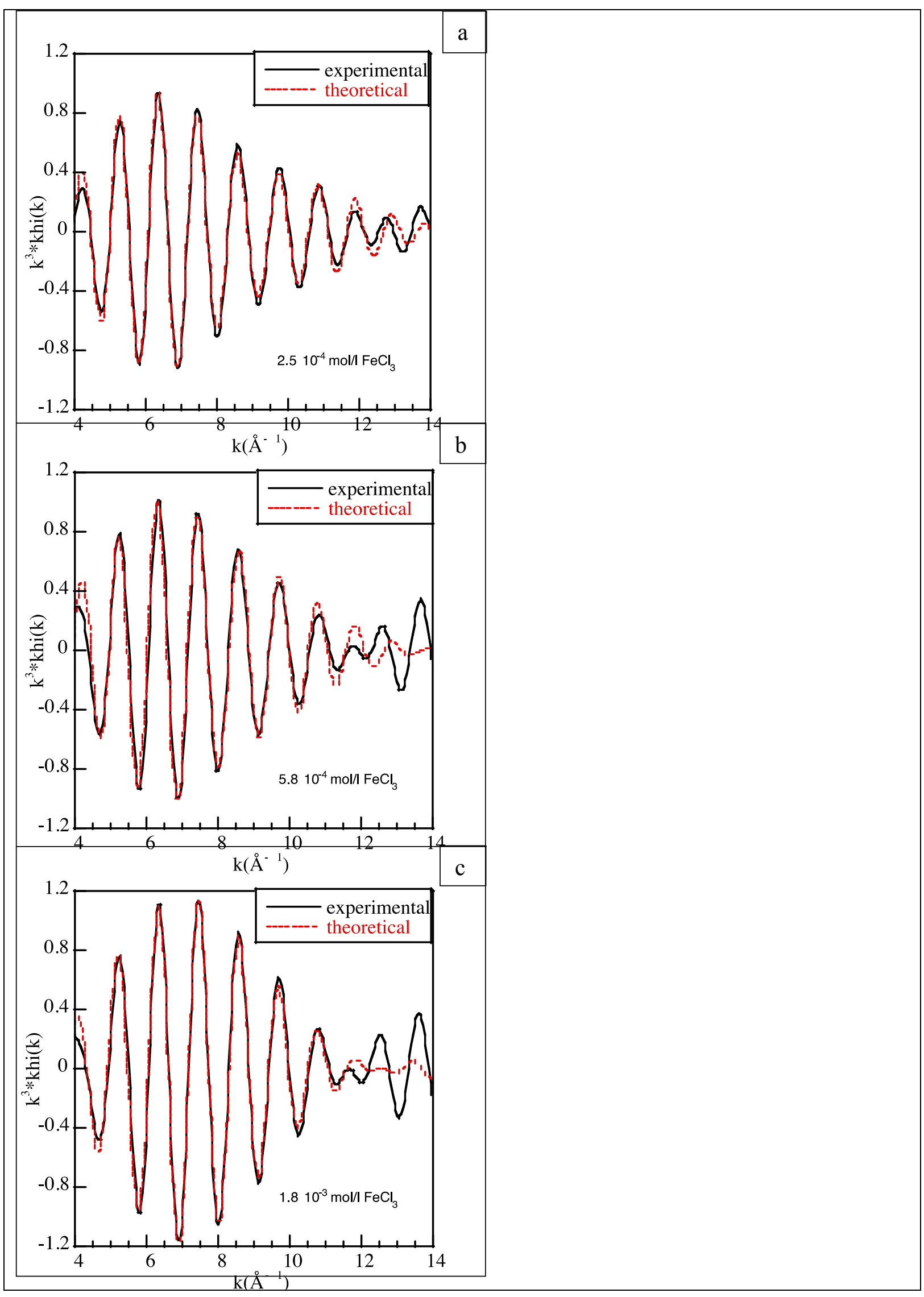

Figure 7. Experimental and calculated curves for the second coordination shell of iron. 


\section{Destabilization mechanism}

The identification of iron-rich colloids as the effective coagulant species for municipal sewage material seems relatively straightforward. It should nevertheless be emphasized that their size and chemistry change drastically with ferric chloride concentration as the formation of Fe-hydrolyzed species strongly depends on the amount of incorporated complexing ions and $\mathrm{pH}$. Such a variability of coagulant species suggests that the destabilization mechanism might also evolve with Fe-concentration. In general, two majors mechanisms are invoked to explain coagulation with hydrolyzing metal salts: at low $\mathrm{pHs}$, charge neutralization of anionic colloidal material with positively charged metal hydrolyzed species is thought to occur, whereas at higher coagulant dosages and $\mathrm{pH}$, precipitation of amorphous metal hydroxide is assumed to enmesh colloidal particles [53]. In our case, $\mathrm{Fe}-\mathrm{PO}_{4}$ hydrolyzed species involved in the coagulation process are likely to be positively charged. Indeed, the polycation formed from one phosphate and two iron dimers is charged 7+ [52]. More generally, anions such as sulfate are known to improve the precipitation of iron(III)-phosphate in acidic conditions [8]. The coagulation of municipal sewage with ferric chloride should then be accomplished by a charge neutralization phenomenon. Experimental evidence for such a destabilization mechanism is usually obtained from electrophoretic studies [54]. Figure 8 shows the effect of ferric chloride concentration on the electrophoretic mobility (EM) of municipal sewage. The mobility of aggregates is negative and increases slightly at low coagulant dosages. It then remains fairly constant in the $\left[3.810^{-4}-7.810^{-4} \mathrm{M}\right]$ concentration range, becomes gradually less negative above OCC, and is reversed in the restabilization domain. This pattern indicates that charge neutralization participates in the destabilization of sewage colloids. However, even though maximum DOC elimination is observed near neutral electrophoretic mobility, the optimum turbidity removal is achieved with negative EM.

Recent work with humic-like compounds bearing a known acidity and coagulated with $\mathrm{Al}_{13}$ polycations [55], revealed that settleable aggregates with an overall charge balance but negative electrophoretic mobility were obtained at OCC. Such a behavior was explained by a reconformation of organic macromolecules in contact with coagulant species as supported by pyrene fluorescence data. In view of the amount of organic matter contained in municipal sewage, it is likely that a similar charge neutralization mechanism with reconformation of organic polymers, is operating during the treatment of municipal sewage with ferric chloride. 


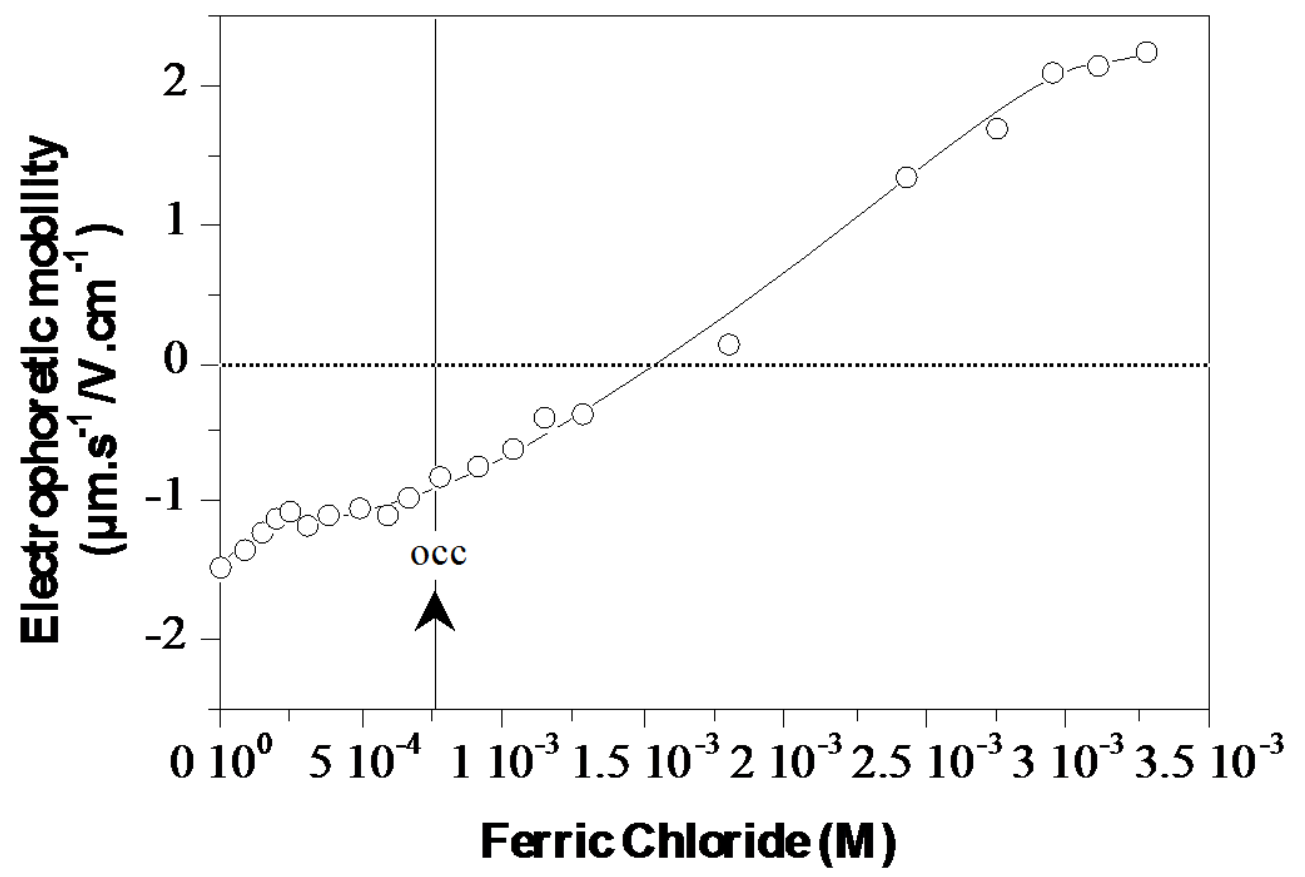

Figure 8. Aggregate electrophoretic mobility as a function of ferric chloride concentration.

The destabilization mechanism may also be inferred from the behavior of coagulated sewage under agitation. Indeed, the evolution of floc size under cyclic changes of stirring allows to distinguish between charge neutralization and bridging of colloid particles with the coagulant species [56], [57], [58], [59] : a definite and reversible stable average floc size is reached for a given shear rate in the case of charge neutralization, whereas bridging within aggregates is associated with an irreversible floc dynamics and a partial re-formation of flocs after shearing.

Figure 9 shows the effect of consecutive cyclic step changes in stirrer speeds from 100 to $200 \mathrm{rpm}$ and vice versa during 15 min periods, for samples of sewage coagulated around OCC and under excess coagulant. In both cases, it is clear that a stable floc size is reached for a given stirring rate, which substantiates a charge neutralization mechanism for coagulation of municipal sewage with ferric chloride. 


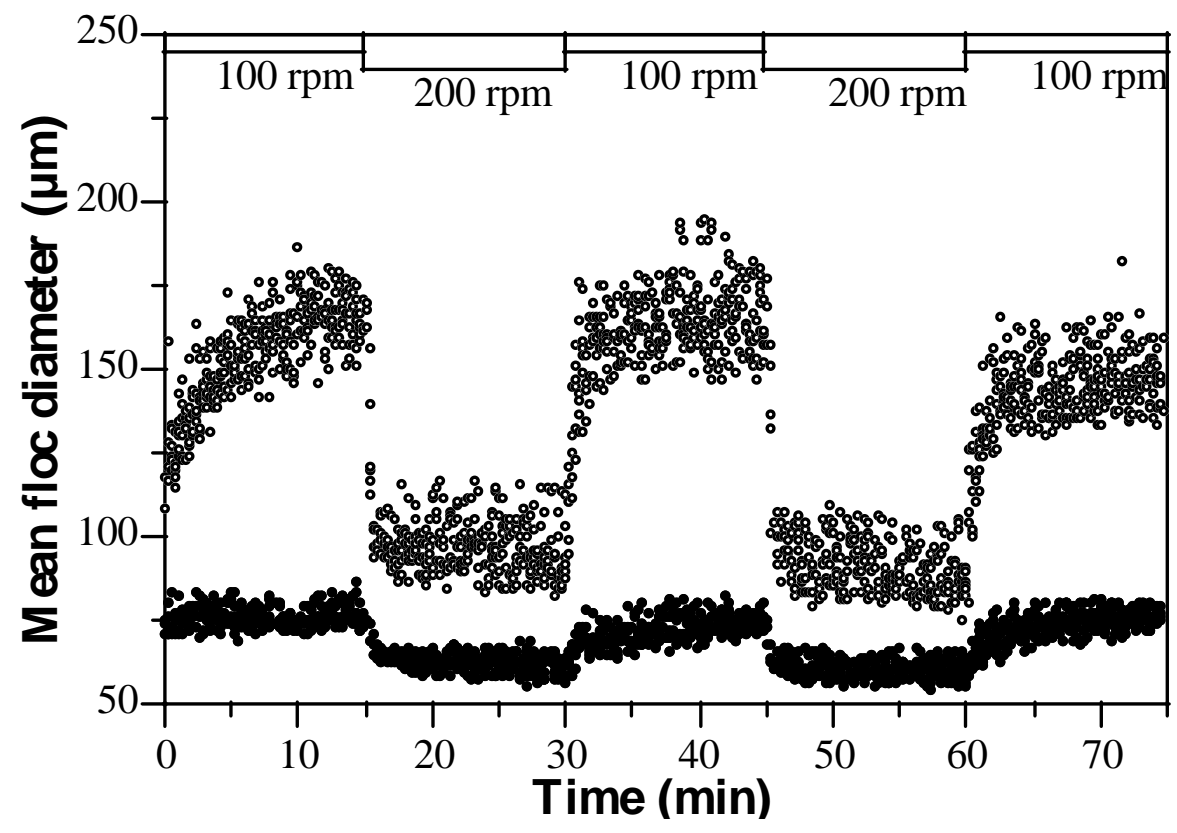

Figure 9. Variation of average floc size as a function of time during consecutive cyclic step changes in agitation intensity. $4.110^{-4} \mathrm{M}\left(\mathrm{FeCl}_{3}\right) \bigcirc 1.910^{-3} \mathrm{M}\left(\mathrm{FeCl}_{3}\right)$.

\section{CONCLUDING REMARKS}

The results reported in this study show unambiguously that the nature of coagulant species formed during the treatment of municipal sewage with ferric chloride, drastically varies with $\mathrm{Fe}$ concentration. At low and moderate coagulant dosages, the formation of coagulant species is strongly influenced by the reactions between the hydrolyzing metal species and the anions contained in raw water, and to a lesser extent by organic colloids. In contrast, at higher dosages, the hydrolyzed species become similar to that obtained during base-neutralization of pure salts of the metal coagulant. Nevertheless, the destabilization mechanism remains the same in the whole range of investigated concentrations, and can be compared with an overall charge neutralization of colloids by positive coagulant species.

Identification of various coagulant species clearly represents an important step that may help to explain the low efficiency removal of dissolved organic matter usually observed in water treatment. Obviously, a similar work should be undertaken with river or lake waters to extend this approach to drinking water treatment. It would also be interesting to investigate 
aggregation kinetics associated with the various interacting coagulant species, as it may open new perspectives in the formulation of commercial coagulants.

Acknowledgements: Elf Atochem is gratefully acknowledged for providing CLARFER. A.G. E., B.S.L., and E.M-P. wish to express sincere thanks to Valérie Briois (LURE) for her help during the EXAFS experiments. The authors gratefully acknowledge the authorization of sampling granted by the Grand Nancy Urban Community. 


\section{REFERENCES}

[1] Mattson S. Cataphoresis and the electrical neutralization of colloidal material. J. Phys. Chem 1928; 32: 1532-1552.

[2] Bottero J.Y., Cases J.M., Fiessinger F., Poirier J.E. Studies of hydrolyzed aluminum chloride solutions. 1; Nature of aluminum species and composition of aqueous solutions. J. Phys. Chem 1980; 84: 2933-2939.

[3] Bottero J.Y., Tchoubar D., Cases J.M., Fiessinger F. Investigation of the hydrolysis of aqueous solutions of aluminum chloride. 2. Nature and structure by small angle X-ray scattering. J. Phys. Chem 1982; 86: 3667-3673.

[4] Bottero J-Y., Tchoubar D., Arnaud M. and Quienne P. Partial hydrolysis of Ferric Nitrate Salt. Structural investigation by Dynamic Light Scattering and Small-Angle X-ray Scattering. Langmuir 1991; 7: 1365-1369.

[5] Bottero J-Y., Manceau A., Villieras F. \& Tchoubar D. Structure and mechanisms of formation of $\mathrm{FeOOH}(\mathrm{Cl})$ polymers. Langmuir 1994; 10: 316-319.

[6] Michot L.J., Montargès-Pelletier E., Lartiges B.S., Espinose de la Caillerie J.B., Briois V. Formation mechanism of the $\mathrm{Ga}_{13}$ Keggin ion: a combined EXAFS and NMR study. J. Am. Chem. Soc. 2000; 122: 6048-6056.

[7] Tchoubar D., Bottero J.Y., Quienne P., Arnaud M. Partial hydrolysis of ferric chloride salt. Structural investigation by photon-correlation spectroscopy and small angle X-ray scattering. Langmuir 1991; 7: 398-402.

[8] Hsu P. Complementary role of iron (III), sulfate and calcium in precipitation of phosphate from solution. Environmental letter 1973; 5 (2): 115-136.

[9] Rose J., Manceau A. Bottero J-Y., Masion A. \& Garcia F. Nucleation and Growth Mechanisms of the $\mathrm{Fe}$ Oxyhydroxide in the presence of $\mathrm{PO}_{4}$ ions. 1. Fe K-Edge EXAFS Study. Langmuir 1996; 12: 6701-6707. 
[10] Parker D.R. and Bertsch P.M. Formation of the " $\mathrm{Al}_{13}$ " Tridecameric polycation under diverse synthesis conditions. Environ. Sci. Technol. 1992; 26: 914-921.

[11] Rose J., Flank A-M, Masion A., Bottero J-Y and Elmerich P. Nucleation and growth mechanisms of Fe oxyhydroxide in the presence of PO4 ions. 2. P K-edge EXAFS study. Langmuir 1997; 13: 1827-1834.

[12] Lartiges B.S., Bottero J.Y., Derrendinger L.S., Humbert B., Tekely P., Suty H. Flocculation of colloidal silica with hydrolyzed aluminum: a ${ }^{27} \mathrm{Al}$ solide state NMR investigation. Langmuir 1997; 13: 147-152.

[13] Masion A., Thomas F., Tchoubar D., Bottero J.Y., Tekely P. Chemistry and structure of $\mathrm{Al}(\mathrm{OH}) /$ organic precipitates. A small angle X-ray scattering study. 3. Depolymerization of the $\mathrm{Al}_{13}$ polycation by organic ligands. Langmuir 1994; 10: 4353-4356.

[14] Molis E., Thomas F., Bottero J.Y., Barrès O. and Masion A. Chemical and structural transformation of aggregated A113 polycations, promoted by silicate ligand. Langmuir 1996; 12: $3195-3200$.

[15] Masion A., Vilgé-Ritter A., Rose J., Stone W.E.E., Teppen B.J., Rybacki D., Bottero J.Y. Coagulation-flocculation of natural organic matter with Al salts: speciation and structure of the aggregates. Environ. Sci. Technol 2000; 34: 3242-3246.

[16] Vilgé-Ritter A., Rose J., Masion A., Bottero J-Y and Lainé J-M. Chemistry and structure of aggregates formed with Fe-Salts and natural organic matter. Colloids and surfaces 1999; 147: 297- 308.

[17] Teo B.K. EXAFS: Basic principles and data analysis, Inorganic Chemistry Concepts Series; Springer-Verlag: New York 1986; 9.

[18] Michalowicz A. Methods and Softwares for X-ray Absorption Spectra Analysis. Applications for studying local order and crystalline disorder in inorganic materials. $\mathrm{PhD}$ Thesis, Université Paris Val de Marne; 1990: 211-241. 
[19] Kemoun A., Lusseyran F., Skali-Lami S., Mahouast M., Mallet J., Lartiges B., Lemelle L., Bottero J-Y. Hydrodynamic field dependence of colloidal coagulation in agitated reactors. Récents progrrès en Génie des procédés 1997; 11 (52): 33-40.

[20] Stumm W. and O’Melia C.R. Stoichiometry of coagulation. JAWWA 1968; 60: 514-539.

[21] Gray K.A., Yao C., O’Melia C.R. Inorganic metal polymers: preparation and characterization. JAWWA 1995; 87: 136-146.

[22] Lefebvre E. and Legube B. Iron (III) coagulation of humic substances extracted from surface waters: effect of $\mathrm{pH}$ and humic substances concentration. Wat. Research 1990; 24 (5): 591-606.

[23] Randtke S.J. Organic contaminant removal by coagulation and related process combinations. AWWA 1988; 80: 40-56.

[24] Collins M.R., Amy G.L., Steelink C. Molecular Weight distribution, carboxylic acidity, and humic substances content of aquatic organic matter: implications for removal during water treatment. Environ. Sci. Technol 1986; 20: 1028-1032.

[25] Dennet K., Amirtharajah, Moran T. and Gould J. Coagulation: its effect on organic matter. Journal AWWA 1996; 88: 129-142.

[26] Bose P. and Reckhow D.A. Adsorption of natural organic matter on preformed aluminum hydroxide flocs. J. Env. Engng 1998; 124: 803-811.

[27] Hawke D., Carpenter P. and Hunter K. Competitive adsorption on goethite in marine electrolytes. Environ. Sci. Technol 1989; 23: 187- 191.

[28] Violante A., Colombo C. and Buondonno. Competitive adsorption of phosphate and oxalate by aluminum oxides. Soil Sci. Soc. Am. J. 1991; 70: 55-65.

[29] Mesuere K. and Fish W. Chromate and oxalate adsorption on goethite.2. Surface complexation modelling of competitive adsorption. Environ. Sci. Technol. 1992; 26 (12): 
[30] Gu B., Schmitt J., Chen Z., Liang L. and McCarthy J. Adsorption and desorption of natural organic matter on iron oxide: mechanisms and models. Environ. Sci. Technol 1994; 28: $38-46$.

[31] Geelhoed J., Hiemstra T. and Van Riemsdijk. Competitive interaction between phosphate and citrate on goethite. Environ. Sci. Technol 1998; 34: 2119-2123.

[32] Specht C., Kumke M., Frimmel F. Characterization of NOM adsorption to clay minerals by size exclusion chromatography. Wat. Research 2000; 34 (16): 4063-4069.

[33] Niemeyer J., Chen Y. and Bollag J-M. Characterization of humic acids, composts, and peat by diffuse reflectance Fourrier -Transform Infrared Spectroscopy. Soil. Sci. Soc. Am. J. 1992; 56: 135-140.

[34] Dignac M-F., Derenne S., Ginestet P., Bruchet A., Knicker H. and Largeau C. Determination of structure and origin of refractory organic matter in bio-epurated wastewater via spectroscopic methods. Comparison of conventional and ozonation treatments. Environ. Sci. Technol 2000; 34: 3389-3394.

[35] Lobartini J. and Tan K. Differences in humic acid characteristics as determined by Carbon-13 Nuclear Magnetic Resonance, Scanning Electron Microscopy, and Infrared analysis. Soil. Sci. Soc. J. 1988; 52: 125-130.

[36] Ricca G. and Severini F. Structural investigations of humic substances by IR-FT, 13CNMR spectroscopy and comparison with maleic ologomer of known structure. Geoderma 1993; 58: 233- 244.

[37] Gu B., Schmitt J., Chen Z., Liang L. and McCarthy J. Adsorption and desorption of different organic matter fractions on iron oxide. Geochemica et Cosmochemica Acta 1995; 59 (2): 219-229.

[38] Yost E., Tejedor-Tejedor M. and Anderson M. In situ CIR-FTIR characterization of salicylate complexes at the Goethite /Aqueous solution interface. Environ. Sci. Technol 1990; 
24: $822-828$.

[39] Zhou L., Yang H., Shen Q., Wong M. and Wong J-W-C. Fractionation and characterization of dissolved organic matter derived from sewage sludge and composted sludge. Environmental Technology 2000; 21: 765- 771.

[40] Tejedor-Tejedor I. \& Anderson M. Protonation of phosphate on the surface of Goethite as studied by CIR-FTIR and Electrophoretic mobility. Langmuir 1990; 6: 602-611.

[41] Dousma j. \& De Bruyn P. Hydrolysis-Precipitation studies of Iron solutions,I. Model for hydrolysis and precipitation from Fe(III) Nitrate solutions. Journal of Colloid and Interface Science 1976; 56 (3): 527-539.

[42] Zhang Z., Boxall C. and Kelsall G.H. Photoelectrophoresis of colloidal iron oxides. 1. Hematite $\left(\alpha-\mathrm{Fe}_{2} \mathrm{O}_{3}\right)$. Colloids and Surfaces A: Physicochemical and Engineering Aspects. 1993; 73: 145-163.

[43] Stevenson F. and Goh K. Infrared spectra of humic acids and related substances. Geochemica et Cosmochemica Acta 1971; 35: 471- 783.

[44] Combes J.M., Manceau A., Calas G., Bottero J.Y. Formation of ferric oxides from aqueous solutions: a polyhedral approach by X-ray absorption spectroscopy. I. Hydrolysis and formation of ferric gels. Geochim. Cosmochim. Acta 1989; 53: 583-594.

[45] Manceau A. and Drits V. Local structure of Ferrihydrite and Feroxyhite by EXAFS spectroscopy. Clay Minerals 1993; 28; 165-184.

[46] Persson P., Nilsson N. and Sjöberg S. Structure and bonding of orthophosphate ions at the iron oxide -aqueous interface. Journal of Colloid and Interface Science 1996 ;177: 263275.

[47] Lienemann C.P., Heissenberger A., Leppard G.G., Perret D. Optimal preparation of water samples for the examination of colloidal material by transmission electron microscopy. Aqua. Microb. Ecol 1998; 14: 205-213.

[48] Lienemann C-P., Monnerat M., Dominik J. and Perret D. Identification of stoichiometric iron-phosphorus colloids produced in a eutrophic lake. Aquatic Sciences 1999; 61: 133- 149. 
[49] Perret D., Gaillard J-F., Dominik J. and Atteia O. The diversity of natural hydrous Iron oxides. Environ. Sci. Technol. 2000; 34: 3540-3546.

[50] He Q., Leppard G., Paige C. and Snodgrass W. Transmission electron microscopy of a phosphate effect on the colloid structure of iron hydroxide. Wat. Research. 1996; 30 (6): 1345- 1352.

[51] Hsu P. Comparison of iron (III) and aluminum in precipitation of phosphate from solution. Water research 1976; 10: 903-907.

[52] Lente G., Magalhaes M.E. and Fabian I. Kinetics and mechanism of complex formation reactions in the Iron (III) - Phosphate ion system at large Iron (III) excess. Formation of a tetranuclear Complex. Inorg. Chem 2000; 39: 1950-1954.

[53] Dempsy B.A., Ganho R.M., O’Melia C.R. The coagulation of humic substances by means of aluminum salts. JAWWA1984;76: 141-150.

[54] Black A.P. and Chen C.L. Electrophoretic studies of coagulation and flocculation of river sediment suspensions with aluminum sulfate. JAWWA 1965; 57: 354-362.

[55] Kazpard V., Lartiges B.S., Görner T., Frochot C., Viriot M.L., Bersillon J.L. Aggregation of Humic-like macromolecules with polycations ( $\mathrm{Al}_{13}$ and $\left.\mathrm{PEI}\right)$ : $\mathrm{A}$ combined pyrene fluorescence, electrophoretic mobility and SEC investigation. Water Research 2003; Submitted.

[56] Tomi D. and Bagster D. The behaviour of aggregates in stirred vessels. II. an experimental study of the flocculation of Galena in a stirred tank. Trans. I. Chem. E 1978; 56: 9-18.

[57] Gregory J. Polymer adsorption and flocculation in sheared suspensions. Colloids Surfaces 1988; 31: 231-253.

[58] Oles V. Shear-induced aggregation and break-up of polystyrene latex particles. J. Colloid Interface Sci 1992; 154: 351-358.

[59] Chaignon V., Lartiges B.S., El Samrani A., Mustin C. Evolution of size distribution and transfer of mineral particles between flocs in activated sludges: an insight into floc exchange dynamics. Wat. Research 2002; 36: 676-684. 